\title{
The Effects of Professional Development on Elementary Students' Mathematics Achievement
}

\author{
Jonathan L. Brendefur ${ }^{1, *}$, Keith Thiede ${ }^{1}$, Sam Strother ${ }^{1}$, Dan Jesse ${ }^{2}$ \& John Sutton ${ }^{2}$ \\ ${ }^{1}$ Boise State University, Boise, USA \\ ${ }^{2} \mathrm{RMC}$ Research Corporation, USA \\ *Correspondence: Boise State University, 1910 University Drive, Boise, ID 83725-1745, USA. Tel: 1-208-426-2468 \\ E-mail: jbrendef@boisestate.edu
}

Received: August 4, 2016

Accepted: September 9, 2016 Online Published: November 24, 2016

doi:10.5430/jct.v5n2p95

URL: http://dx.doi.org/10.5430/jct.v5n2p95

\begin{abstract}
This paper describes the effects of a professional development (PD) program - Developing Mathematical Thinking on student achievement. Six Title I elementary schools with similar demographics, within one school district, were chosen to participate as either a treatment or comparison school. Three schools were chosen to participate in professional development that incorporates effective PD recommendations. All the teachers had to participate in all aspects of the PD, thereby eliminating potential self-selection bias. Using the state standardized achievement test as the before and after measure, results suggest improved student performance after professional development was implemented over a two year period.
\end{abstract}

Keywords: professional development; mathematics; student achievement

Students at the elementary levels are not performing well in mathematics and their overall performance does not improve over time. Based on recent reports, U.S. students are not considered mathematically literate or proficient when compared to national standards and to students from other countries (Lemke et al., 2004; Mullis, Martin, Gonzalez, \& Chrostowski, 2004; NMAP, 2008; NRC, 2001). In 2009 the U.S. National Center for Education Statistics ranked the U.S. behind 30 other countries in students' mathematics proficiency. Several researchers have demonstrated that students who complete kindergarten with an inadequate knowledge of basic mathematics concepts and skills will continue to experience difficulties with mathematics throughout their elementary and secondary years (Duncan et al., 2007; Jordan, Kaplan, Ramineni, \& Locuniak, 2009; Morgan, Farkas, \& Wu, 2009). By fourth grade, student performance is deemed poor based on measures of mathematics (Clements \& Sarama, 2007; Clements, Xiufeng, \& Sarama, 2008; Gersten et al., 2009; NRC, 2009; Reese, Miller, Mazzeo, \& Dossey, 1997). For instance, Mitchell and colleagues describe students at the fourth grade level as consistently performing poorly on low-level items with no improvement by eighth and twelfth grades (Mitchell, Hawkins, Stancavage, \& Dossey, 2000). These studies point to the critical need to adjust mathematics instruction: particularly at the elementary level (Chernoff, Flanagan, McPhee, \& Park, 2007; Ginsburg, Lee, \& Boyd, 2008).

One distal mechanism for improving student achievement is professional development. More closely, professional development affects teachers' beliefs and knowledge (content and pedagogy) and then somewhat their instruction, which then implicitly affects achievement (Desimone, 2009; Desimone, Porter, Garet, Yoon, \& Birman, 2002). This is not to say there are no other factors involved. But this makes examining professional development as a factor influencing achievement an arduous task. The purpose of this paper is to demonstrate the effects of two years of a mathematics professional development program on student achievement. Because instruction is a more direct link to achievement, we first describe the type of instruction we intended teachers to model. For a more thorough description of the PD and effects on teachers' knowledge and instruction see Brendefur et al (2013). Then we describe the professional development elements we constructed to move teachers toward this type of practice. Finally, we demonstrate the effect of this instruction on student achievement using a treatment and comparison group. 


\section{Teaching to Promote Mathematical Understanding}

There have been studies that have shown when teachers teach for understanding, achievement improves (Haycock, 2001; Knapp, 1995; Newmann \& Associates, 1996). Thus, before building a model for conducting professional development in mathematics, we examined instructional structures that we wanted to observe in teachers' classroom practices. From these structures we then proceeded to build a professional development model to encourage teachers to promote these instructional structures (Brendefur et al, 2013).

Our concept of teaching for understanding is grounded in both a structural and functional perspective (Hiebert et al., 1996). From a structural position on understanding, the aim is for teachers to create conditions within students' classroom experiences for them to cognitively organize new information in ways that allow them to order and build a well-connected network of understanding. From a functional perspective, we focus on providing the types of tasks and activities that place students in situations where, through articulation, they are able to reflect on how they solve problems and construct relationships.

In other words, in order for students to develop understanding, teachers must attend to both the structural and functional aspects of teaching the content within their classrooms. As Carpenter and Lehrer (1999) argue, "For learning with understanding to occur, instruction needs to provide students the opportunity to develop productive relationships, extend and apply their knowledge, reflect about their experiences, articulate what they know, and make knowledge their own" (p. 32). These components became a foundation for our theoretical framework for instruction - Developing Mathematical Thinking (DMT).

\subsection{Instructional Theory -- DMT}

This section frames an approach to teaching mathematics for understanding. We describe this type of instruction as Developing Mathematical Thinking or DMT. This instructional model for teaching builds on Carpenter and Lehrer's (1999) elements listed above and in addition incorporates notions of "guided reinvention" and "mathematizing" (Freudenthal, 1973, 1991; Treffers, 1987). As Gravemeijer and van Galen (2003) describe, guided reinvention is a process of first allowing students to develop informal strategies and ways to model these approaches for solving problems, and then, by critically examining both these strategies and models, encouraging students to develop more sophisticated, formal, conventional and abstract strategies and algorithms. By comparing solution strategies and examining the relationship between iconic and symbolic models (Bruner, 1964), students learn which manipulations make sense for given contexts and are encouraged to develop more general procedures. Eventually, the contexts fade into the background and the "manipulations themselves ... acquire meaning of their own" (Gravemeijer \& van Galen, 2003, p. 116).

Students are encouraged to make connections between existing knowledge (informal ideas) and new knowledge (more formal mathematical ideas) required by Hiebert \& Carpenter's (1992) concept of structural understanding through solving novel problems. By critically examining their own and others' strategies and models, students are encouraged to build functional understanding, which exemplifies the importance of social interactions in classrooms. "By thinking and talking about similarities and differences between arithmetic procedures, students can construct relationships between them. ... the instructional goal is not necessarily to inform one procedure by the other, but rather, to help students build a coherent mental network in which all pieces are joined to others with multiple links" (Hiebert \& Carpenter, 1992, p. 68).

Closely related to guided reinvention, the DMT instructional method incorporates Treffer's (1987) notions of horizontal and vertical mathematization. Horizontal mathematization occurs when students represent a contextualized problem mathematically in order to find a solution strategy. Vertical mathematization involves taking the mathematical matter to a higher level, and occurs when students make their representations and strategies objects of mathematical examination. Mathematizing covers such activities as generalizing, justifying, formalizing, and curtailing - including, but not limited to, developing an abstract algorithm (Gravemeijer \& van Galen, 2003). By focusing on both types of mathematizing in their classrooms, teachers must maintain a focus on the inherent structure of the mathematical ideas that are emerging. In addition, they must address students' misconceptions as they arise so these misconceptions do not hinder the mathematizing progression. One outcome of mathematizing is that teachers connect students' informal ideas, many of which may be developed outside of school, with more formal mathematical ideas. "One would predict that if children possessed internal networks constructed both in and out of school, and if they recognized the connections between them, their understanding and performance in both settings would improve" (Hiebert \& Carpenter, 1992, p. 79).

Such a process starts with carefully chosen tasks - typically contextualized (Doerr, 2006; Larsen \& Bartlo, 2009; 
Simon \& Tzur, 2004). To solve these problems, students must model the situation to some degree. Rather than beginning with the standard algorithms and attempts to concretize them, teaching begins with students' commonsense solutions to contextual problems that are real for them. By reflecting on the solution procedures they have used, students develop and are introduced to more sophisticated models and procedures that they can also use in other situations (Gravemeijer \& van Galen, 2003, p. 114). In other words, teaching typically starts with considering students' ideas about solving real world problems and continues by keeping students' ideas as the foundation for later years.

Mathematical knowledge originates from students' attempts to model contextual situations. These models then become the basis for solving related problems as well as a means of support for more formal mathematical reasoning (Gravemeijer \& van Galen, 2003). As Cobb (2000) described, this use of modeling “...implies a shift in classroom mathematical practices such that ways of symbolizing developed to initially express informal mathematical activity take on a life of their own and are used subsequently to support more formal mathematical activity in a range of situations" (p. 319). In this way, modeling is a fundamental process in learning mathematics. However, this view of models and modeling contrasts with current practices in mathematics instruction in which models are used to "concretize expert knowledge" (Gravemeijer \& van Galen, 2003, p. 118) and contextual problems are presented only after students have mastered traditional ways of solving problems. In this way, guided reinvention and mathematizing via the use of mathematical modeling, turns the focus toward students' ways of using models rather than on teacher or curriculum created ways of using models.

Through enacting aspects of 'guided reinvention' and 'mathematizing' teachers develop a classroom practice that is based on the tenets of teaching for understanding. We believe their practice hinges on five key elements of classroom practice: the centrality of students' ideas, encouraging multiple solution strategies and models, pressing students conceptually, addressing misconceptions and maintaining a focus on the structure of the mathematics (Brendefur, 2008). By focusing their teaching practices on these five key elements (see Figure 1), elementary teachers shift their attention toward students' informal strategies for solving problems and the mathematical connections between multiple mathematical models and formal solution strategies. By encouraging students to use informal knowledge and experiences, student misconceptions are bound to arise. By acknowledging and addressing them, teachers encourage students to make sense of and correct their flawed ways of thinking, rather than glossing over them or ignoring them completely. The five key elements grow out of the concepts that mathematics exists of underlying inherent related constructs and that students learn mathematics by creating web-like or hierarchical structures for these constructs.

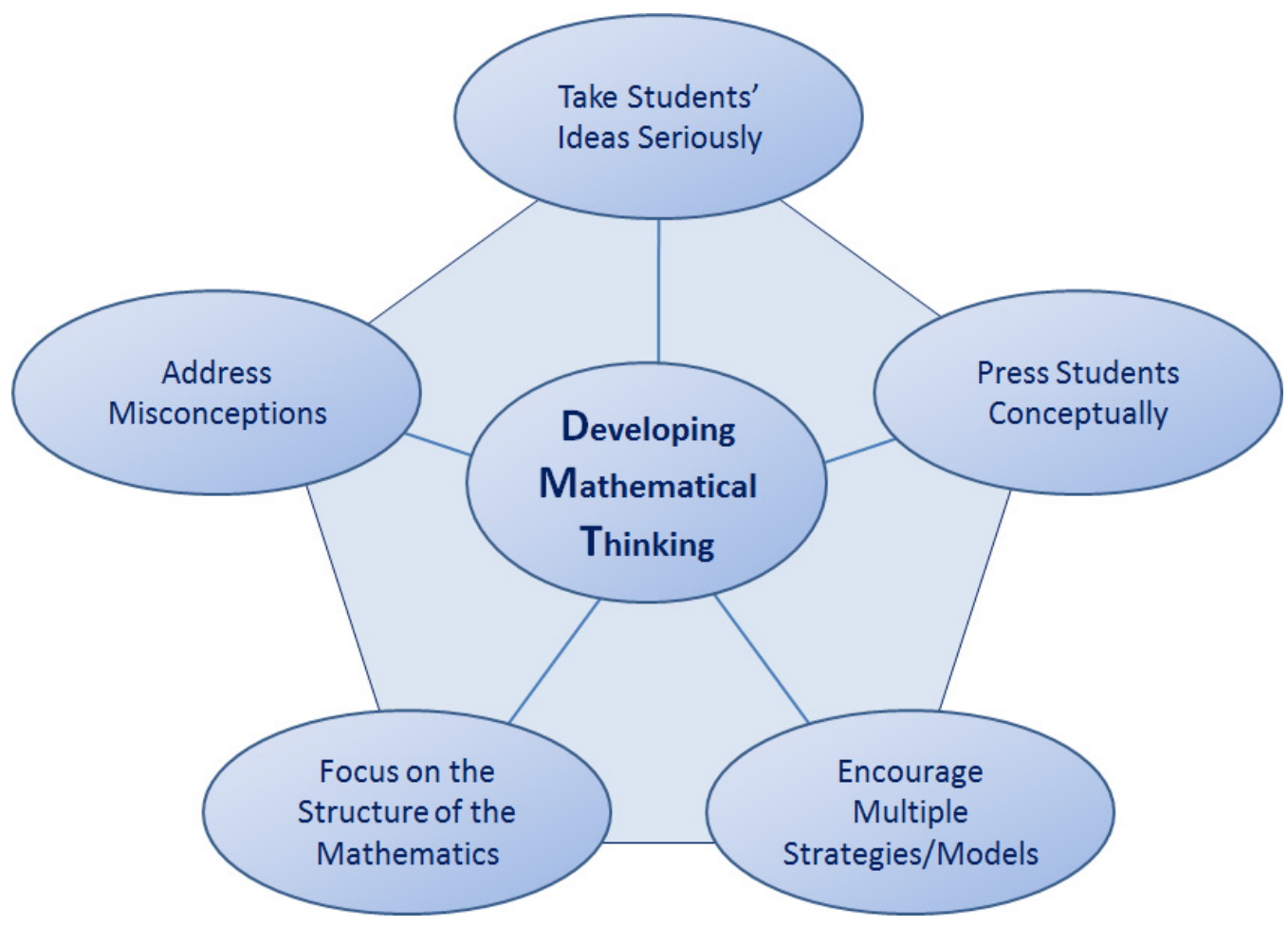

Figure 1. Components of Developing Mathematics Thinking 


\section{Professional Development to Promote DMT Instruction}

In order for teachers to begin building these highly technical skills, the professional development must build teachers' knowledge of (a) the different situations to put students in to progressively formalize their thinking, (b) different ways students will respond to these mathematical situations, (c) how to build their initial, usually informal, ways of modeling the problem, (d) how to press their understanding, and (e) how to find or create additional situations to enable continual deeper understanding.

Building on the literature reviews on instructional practices to promote mathematical understanding, we constructed a professional development framework to develop teachers' mathematical thinking and pedagogy. To begin, we used Simon's (1995) conceptual model for learning and teaching referred to as hypothetical learning trajectories (HLT) (Baroody, Cibulskis, Lai, \& Li, 2004; Clements \& Sarama, 2004; Hiebert et al., 1997; Simon, 1995). Generally, an HLT describes the mathematical path teachers envision their students taking as they explore specific mathematical domains. HLT's include theories of children's initial ideas, a sequence of instructional tasks, and descriptions of children's progressions of learning and thinking.

We prepared teachers to explore the terrain of mathematics in new ways. We encouraged them to examine "connections among concepts, their representations and the various contexts in which they may be embedded" (Schifter, 1996, p. 3). As part of this process, it was crucial that teachers began to question their own mathematical knowledge (typically procedural) and the knowledge (based on real experiences) that their students bring to the classroom. We did this by encouraging teachers in both explicit and embedded professional development to enact the five elements of classroom practice described above and by helping them develop their own learning trajectories (Gravemeijer \& van Galen, 2003; Simon, 1995) for various mathematical topics.

More specifically, according to Simon (2005), HLT's are made up of three components: the learning that defines the direction, the learning activities, and the hypothetical learning process - a prediction of how the students' thinking and understanding will evolve in the context of the learning activities. Baroody, et al (2004) emphasize that HLT's should focus on the "big ideas" and should incorporate both linear, or "ladder-like" trajectories, as well as multiple path or "branching tree" trajectories (p. 254). Hiebert, et al (1997) describe hypothetical learning trajectories as "...the teacher's vision of the mathematical path that the students might take, and its hypothetical nature comes from the fact that it is based on the teacher's guess about how learning might proceed along the path. The trajectory guides the teacher's task selection, but feedback from students and the teacher's assessments of the residues that are being formed lead to revisions in the trajectory. Tasks are selected purposefully, but the sequence can be revised" (p. 34).

As an example, we posed addition problems through join and separate versus part-whole and compare problem types. Teachers first had to model or learn how to model the solution paths by using enactive, iconic and symbolic representations. Next, teachers examined student work across grade levels to build trajectories of how students solve these situations. Finally, teachers had to articulate different hypothesized instructional decisions based on what students were doing. This element was very intense and difficult for teachers. Most of them wanted to just tell the students one, usually symbolic, way of solving the problem. Instead, we discussed different tasks to pose to students based on how they solved the problem, different ways to notate their thinking, ways to help them formalize their thinking and modeling, and how to extend or simplify the situation to meet the demands of all students.

As Gravemeijer (2004) points out, HLT's are tailored to a specific classroom and teacher at a given time. (For this reason, developing HLT's for general use may be a misuse of the HLT concept.) Gravemeijer (1999) develops another concept, local instructional theory (Gravemeijer \& van Galen, 2013), to refer to more general instructional sequences that may be useful on a larger scale. "The idea is that teachers use their insight in the local instruction theory to choose instructional activities and to design HLT for their own students. This is ultimately the goal of our professional development: to help teachers learn to utilize LIT's by enhancing teachers' understanding of mathematics, pedagogy, and children's thinking.

Here is a second example of a professional development task that highlights the mathematizing process to build teachers' knowledge and develop their own hypothetical learning trajectories. We share a modified task from Carpenter and colleagues (2000): Lizzie collects lizards and beetles. She has 8 creatures in her collection so far. All together they have 36 legs. How many of each kind of creature does she have in her collection? We also provide two extension tasks: (a) If there are 8 creatures, what are all the different possibilities of lizards and beetles? and (b) If there are 36 legs, what are all the different possibilities of creatures? Teachers were, first, asked to solve this problem using any method they would like. Elementary teachers tended to solve it using these strategies listed in order of greatest use to least use: pictures, guess and check, table format, and systems of equations (see Figure 1). Please note that there are other ways, such as graphing and other table formats, but these were the most typical. Teachers were then 
asked to present these methods on the whiteboard. We did this from what could be considered the more informal method (drawing) to the more formal method (systems). This was the first element of horizontally mathematizing the problem.

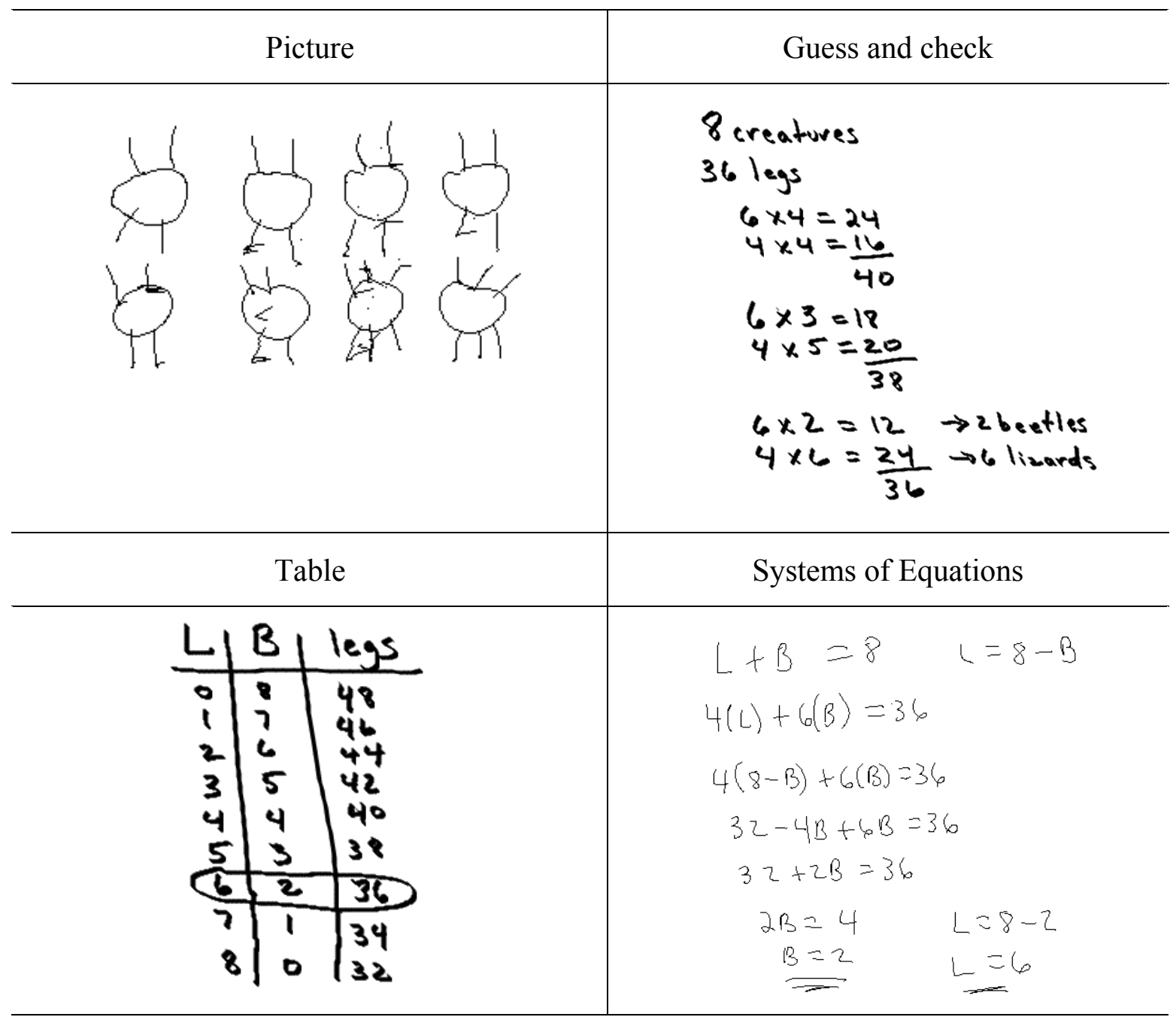

Figure 2. Samples of Teachers' Work

Next, we asked teachers to explain the similarities and differences among the different models and the mathematics being highlighted in the mathematical model. For instance, we pressed teachers to examine the line $(32+2 \mathrm{~B}=36)$ in the systems model in light of the other models. What follows is an important discussion of the mathematics, (a) the 32 is when the drawing is 8 lizards, (b) the $2 \mathrm{~B}$ is the conversion of lizards to beetles by distributing the 2 extra legs needed to make a beetle - twice, which is the next line $(2 \mathrm{~B}=4)$, and $(\mathrm{c})$ the 36 is the target number of legs. During this part of the conversation, we discussed why students might use one method over another and what pedagogical steps should take place to move students from one method to another in order to increase understanding and efficiency. Finally, teachers were asked to practice using a mathematical model that is not familiar to them, while also explaining to group members what each mark, notation, or number represents. This process extends the horizontal mathematizing process to vertical mathematizing.

\subsection{Professional Development in Action}

In this section we discuss the literature on effective professional development. This is followed by a description of how our professional development was framed to include both explicit and embedded situations.

There are numerous articles describing which elements in professional development are most effective (Borko, Koellner, \& Jacobs, 2011; Desimone, 2011; Garet, Porter, Desimone, Birman, \& Yoon, 2001; Hawley \& Valli, 2000; Sztajn, 2011). Although most of the elements are similar, Yoon et al. (2007) describe that much of the research on 
professional development in mathematics has not demonstrated improved student achievement because they lack specific features needed to change teachers' practice. Therefore, we used their six characteristics that need to be evident for professional development to be effective: "coherence, active learning, sufficient duration, collective participation, a focus on content knowledge, and a reform rather than traditional approach" (p. 1). We describe each one briefly.

Coherence depicts the strength of the professional development. If teachers do not perceive the professional development and intervention models to be a connected and an integral part of what the school is doing or encouraging, then the features being introduced will not persist over time (Garet et al., 2001). For coherence to be built, professional development activities should focus on standards (currently in the U.S. the common core state standards (NGA, 2010b)) and testing, but also on methods to increase the learning of marginal groups of students (Linn, Gill, Sherman, Vaughn, \& Mixon, 2010).

Active learning includes engagement in tasks that improve teachers' own knowledge of the mathematics, covers learning progressions, engages teachers in creating learning trajectories, and encourages articulation and implementation of these ideas (Garet et al., 2001; Hawley \& Valli, 2000). Tasks that improve teachers' knowledge must force them into cognitive dissonance and, then, allow them to integrate the new ideas in a way that makes sense mathematically and pedagogically. For example, an initial task might be to write two contextual problems for the number sentence $2+5=\square$ and explain (a) the differences in how students will respond to each context and (b) what mathematical models (enactive and iconic) might be introduced in what order for young students. In order to respond to this task, teachers must be able to compose or write a join and a part-whole context.

Sufficient duration refers to the amount of time teachers spend in professional development, which includes workshops and institutes as well as on-going activities throughout the year. Desimone (2011) states that there should be a minimum of 20 hours, while others say even longer (Yoon et al., 2007). However, to be sufficient the amount of time spent in professional development must connect to a change in teacher outcomes: beliefs, knowledge, and/or practices.

Collective participation indicates that teachers and administrators must come together to create professional learning communities. When teachers are supported by their building and district administers, it is demonstrated that instructional practices improve and student achievement increases (Adajian, 1995).

Knowledge, both content and pedagogical, of educators needs to be well developed in areas of the structure of the mathematics and how young students learn mathematics (Ball, Hill, \& Bass, 2005; Ma, 1999). When professional development integrates content and pedagogical knowledge and how students learn procedurally and conceptually, then instruction tends to improve as does student achievement (Ball, Thames, \& Phelps, 2008; Kennedy, 1998).

Focusing on reform practices and building on the mathematical practices outlined in the Common Core State Standards for Mathematics (NGA, 2010) rather than on traditional approaches within professional development refers to teaching for understanding. Here, elements within the professional development must focus on building teachers' understanding and practices to create situations for their students to problem solve, make connections within and outside of mathematics, use multiple mathematical models, and reason mathematically (Hiebert \& Carpenter, 1992; Hiebert et al., 1997; Simon, 2006).

\subsection{Components of the DMT Professional Development}

Each year the DMT professional development consisted of two components: (a) a one week or 45 hour intensive workshop focused on mathematics, student thinking, and pedagogy and (b) ongoing or embedded follow-up professional development in the school throughout the academic year. More specifically, the summer workshop consisted of topics that engaged teachers to understand the mathematics (number and early algebra topics in year 1 and measurement and geometry in year 2) and how students learning progresses on these topics over the elementary years. Pedagogically, teachers learned how to construct their classrooms using the 5 DMT dimensions: take students' ideas seriously (asking them to explain their thinking and others'), focus on conceptual understanding as well as procedural (asking students to explain how, why, and when the methods work), promote multiple mathematical models (encouraging the connection among and progression of using more sophisticated methods), address misconceptions (asking students to determine when an idea does not work and why), and focus on the structure of the mathematical topics (such as composing, decomposing, iteration, partitioning, and unitizing). Once teachers were back in school, we setup a three-part plan for working with the teachers in their schools. Two staff members met with teachers six times throughout the year to plan and reflect on a unit - nicknamed Unit Study. Grade-level bands of teachers, typically 6 to 12 teachers met for two hours at a time. We began by focusing on a common task that teachers gave their students. We 
would sort the student results into three piles: proficient or advanced responses, mistakes and misconceptions, and major errors or concerns. We would use the second pile to build instructional techniques for addressing these misconceptions in the classroom. This would typically lead into a short professional development period as well. Then we would build pre and posttest items based on Webb's (2007) Depth of Knowledge categories (skills, concepts, strategic, and extended). We would then analyze the pre/posttest data from the previous unit to look for trends. Based on needs, we would discuss and create activities or warm-ups to continue addressing deficits found. In between the Unit Studies, we would then meet with teachers in their classrooms to co-teach lessons, observe their instruction or work with a small group of students. In all these situations, we would work with the teachers before and after the lessons to discuss trends and suggest next steps. We were in each of the project schools approximately once a week.

As Desimone (2009) described we first evaluated the effectiveness of the DMT professional development program on teachers' knowledge and practices. DMT was determined to increase teachers' knowledge of (a) number and operations, (b) measurement and geometry, and (c) probability and statistics. This knowledge was measured before the 45-hour summer professional development course was taken and then again six months after to provide a more a accurate portrayal of teachers' change in knowledge. Change in knowledge was determined to be positively related to dimensions of teaching practice for number and operations, measurement and geometry, probability and statistics. That is, those teachers with greater changes in knowledge demonstrated more effective instruction Brendefur et al, 2013).

After demonstrating changes in knowledge and practice, this study documents the impacts of the DMT professional development upon mathematics achievement of students (as measured by the state standardized test of mathematics). In particular, this study compares student achievement for teachers who participated in the program, compared to teachers in similar schools from the same district, who did not participate in the program.

\section{Method}

\subsection{Setting}

Table 1. School Demographics for Treatment Schools

\begin{tabular}{|c|c|c|c|c|c|c|}
\hline & \multicolumn{3}{|c|}{ Treatment Schools } & \multicolumn{3}{|c|}{ Comparison Schools } \\
\hline & Adams & Grant & Hayes & Monroe & Polk & Roosevelt \\
\hline Grade Levels & $\mathrm{K}-5$ & $\mathrm{~K}-5$ & $\mathrm{~K}-5$ & $\mathrm{~K}-5$ & $\mathrm{~K}-5$ & $\mathrm{~K}-5$ \\
\hline Enrollment & 397 & 490 & 570 & 504 & 487 & 591 \\
\hline Teachers & 18 & 21 & 21 & 24 & 21 & 23 \\
\hline \multicolumn{7}{|l|}{ Race/Ethnicity } \\
\hline White & $48 \%$ & $36 \%$ & $28 \%$ & $41 \%$ & $46 \%$ & $52 \%$ \\
\hline Latino & $49 \%$ & $63 \%$ & $70 \%$ & $57 \%$ & $51 \%$ & $46 \%$ \\
\hline Black & $1 \%$ & $1 \%$ & $0 \%$ & $.8 \%$ & $1.2 \%$ & $.5 \%$ \\
\hline Asian & $1 \%$ & $0 \%$ & $0 \%$ & $0 \%$ & $0 \%$ & $1 \%$ \\
\hline Native Am. & $1 \%$ & $0 \%$ & $0 \%$ & $0 \%$ & $1 \%$ & $0 \%$ \\
\hline Pacific I. & $1 \%$ & $0 \%$ & $1 \%$ & $0 \%$ & $0 \%$ & $0 \%$ \\
\hline Other & $1 \%$ & $0 \%$ & $0 \%$ & $0 \%$ & $0 \%$ & $0 \%$ \\
\hline E.L.L. & $15 \%$ & $30 \%$ & $30 \%$ & $21 \%$ & $11 \%$ & $11 \%$ \\
\hline Migrant & $1 \%$ & $3 \%$ & $1 \%$ & $2 \%$ & $1 \%$ & $2 \%$ \\
\hline Languages & $\mathrm{Sp} / \mathrm{En}$ & $\mathrm{Sp} / \mathrm{En}$ & $\mathrm{Sp} / \mathrm{En}$ & $\mathrm{Sp} / \mathrm{En}$ & $\mathrm{Sp} / \mathrm{En}$ & $\mathrm{Sp} / \mathrm{En}$ \\
\hline Free/Reduced & $75 \%$ & $85 \%$ & $89 \%$ & $72 \%$ & $75 \%$ & $63 \%$ \\
\hline Title & Yes & Yes & Yes & Yes & yes & Yes \\
\hline Special Educ & $8 \%$ & $7 \%$ & $7 \%$ & $8 \%$ & $10 \%$ & $8 \%$ \\
\hline
\end{tabular}

The DMT professional development was conducted in a school district located in Southwestern Idaho where all the schools were Title I schools and had a history of below average performance on the Idaho State Achievement Test 
(ISAT). Table 1 highlights teacher and student characteristics from the six elementary schools involved in the study. The schools ranged from 63 to 89 percent of their students on free and reduced price lunch status and 11 to 30 percent English Language Learners. Before the project began, we worked with the superintendent and principals to select three schools to participate in the DMT professional development. Mathematics performance was not used as a criterion for selecting participating schools; however, the principal's enthusiasm to participate in the professional development may have been influenced by knowledge of poor performance on the ISAT, which would explain differences in pretest achievement performance across schools. Central administration and building administrators at each of the treatment schools agreed that $100 \%$ of their faculty would participate in all aspects of the program, including attendance to the summer workshop and all in-school activities. One additional note is that due to the transient nature of students in the district, the number of students classified as having multiple years in DMT waned.

\subsection{Participants and Design}

The DMT professional development occurred in three consecutive years at three schools. Two of the authors conducted the professional development and the other three authors were independent evaluators of the project. Although all the teachers at the treatment schools participated in the DMT professional development, the test of student achievement is administered only to students in grades 3 through 5 in K-5 elementary schools; therefore, our student-level analysis of achievement used data from these students.

At the time of the DMT professional development the district had instituted a highly scripted reading program. Adoption of the reading program imposed constraints on teachers in all schools in the district. In particular, teachers were mandated to teach reading and language arts in the blocks in the morning. The imposed structured schedule meant all teachers taught mathematics in a 45 minute instructional block during the afternoon. In addition to this block of time, teachers across the schools were also given 20 minute blocks to conduct specific group level remediation or to pre-teach upcoming reading concepts. These two factors, placing the teaching of mathematics in the afternoon and decreasing the amount of time given to mathematics instruction, constrain the ability to increase student achievement.

Students were categorized according to how many years they had teachers participating in the DMT professional development. Teachers' years of exposure to DMT was an independent variable in the design. There were three groups: students who had two years of DMT teachers $(n=131)$, those who had one year of DMT teachers $(n=293)$, and those who had no years of DMT teachers, which are students from the non-DMT schools $(n=569)$. The groups that received any DMT professional development were combined for an omnibus test of the effectiveness of the professional development. Time was a repeated-measures variable in the design, with achievement measured at three different times (pretest - prior to DMT professional development, posttest 1 and posttest 2 - after the first and second year of the professional development). Although the DMT professional development spanned three years and should have included four achievement dates, the State did not provide the external evaluators the final year of student achievement data; therefore, we analyzed only three years of data. As we compared achievement across three years, we included only students with complete achievement data for all three years. Thus, we had a 2 (DMT versus no-DMT) x 3 (Time: Pretest, Posttest 1, Posttest 2) design.

Student achievement was the dependent variable in this study and was measured by performance on the mathematics subtest of the ISAT, which was administered each spring to all students in the state in grades 3-10. The mathematics assessment of the ISAT is composed of items that address standards, goals, and objectives for grades 3-10. The goals and objectives for each grade are distributed among five reporting categories: Number and Operations; Concepts and Principles of Measurement; Concepts and Language of Algebra and Functions; Principles of Geometry; and Data Analysis, Probability, and Statistics. The ISAT Mathematics assessment utilizes a multiple-choice format, and a different assessment is administered for each grade level. The scores analyzed here were students' standardized scores relative the State mean at each grade level. That is, for each student, we had a z-score, which represented his or her deviation from the mean score computed across students in Idaho, within the student's grade.

\subsection{Procedure}

Participating teachers attended the week-long workshop during the summer before the beginning of the school year. The first training was held in the summer and in-depth unit planning and in-school professional development began (after the second week of instruction). The ISAT was administered during the spring of each academic year.

Over the course of the three years of the project, DMT staff regularly visited all the teachers in the treatment schools on a regular basis. One staff member was onsite for each school approximately 2 days a month during the school year. On the average, a school received 18 days of contact from a DMT staff member. While in schools, the following actions occurred: (a) once a month Unit Studies with grade level bands that lasted for two hours, and (b) co-teaching episodes 
that included planning, teaching together, and post teaching discussions. Topics discussed were mostly focused on the content presented during the summer professional development.

\section{Results}

We analyzed the student achievement data in a 2 (DMT versus no-DMT) x 3 (Time: Pretest versus Posttest 1 versus Posttest 2) analysis of covariance (ANCOVA), with minority group status and free and reduced lunch status dummy coded and entered as covariates.

There was a significant main effect for DMT group, $F(1,1090)=35.54, p<.001, M S e=2.13$. The main effect for Time was not significant, $F(2,2180)<1, M S e=.21, p=.69$. However, the interaction was significant, $F(2,2180)=20.84$, $M S e=.21, p<.001$. We conducted tests of simple effects to better understand the interaction, while still controlling for minority status and free and reduced lunch.

Student achievement decreased significantly across time for the no-DMT group, $F(2,1132)=3.11, M S e=.23, p=.05$. Follow-up Tukey HSD post hoc tests showed that the decrease was significant across all three times. By contrast, student achievement did not change significantly across time. Thus, as seen in Figure 2, across time the achievement gap between DMT and no-DMT schools decreases with time.

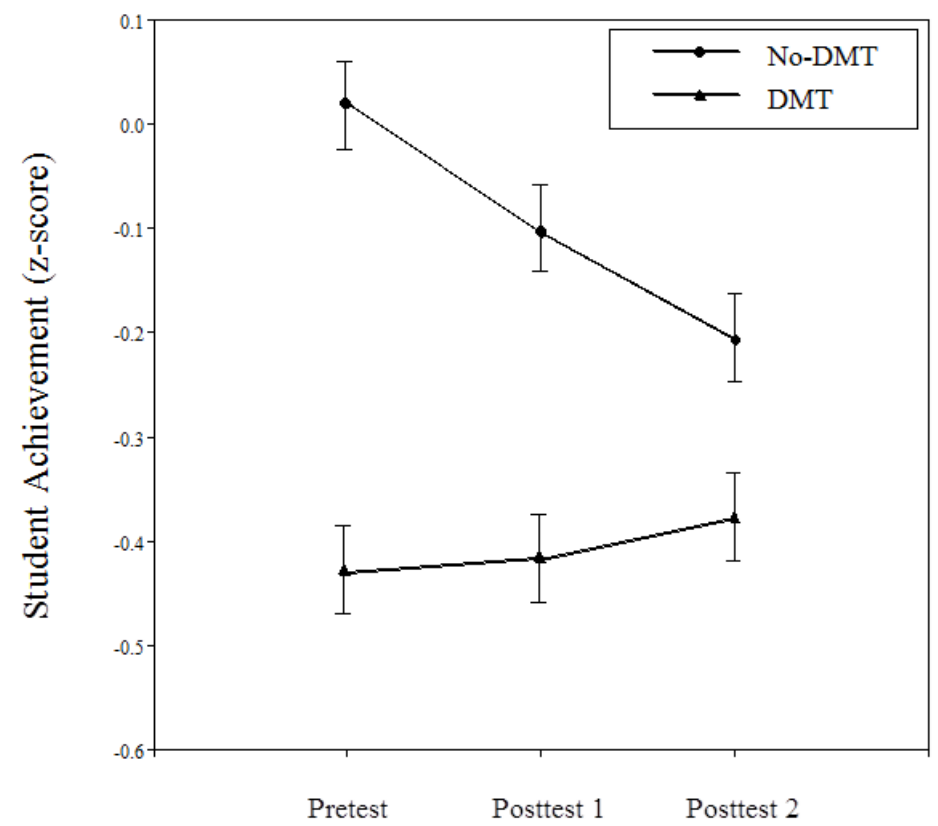

Figure 3. Achievement Data for Students Whose Teachers Participated in the DMT PD and Not

In an ideal situation student would have teachers involved in the DMT professional development for all three years. To examine this best-case scenario, we compared student achievement for those students who had a DMT teacher for all three years and those in the comparison schools. The 2 (DMT three years versus no-DMT) x 3 (Time: Pretest versus Posttest 1 versus Posttest 2) ANCOVA (controlling for minority group status and free and reduced lunch status) revealed a significant main effect for DMT group, $F(1,666)=12.46, M S e=2.21, p=.02$. The main effect for Time was not significant, $F(2,1332)<1, M S e=.23, p=.53$. However, the interaction was significant, $F(2,1332)=20.02$, $M S e=.23, p<.001$. As seen in Figure 3, the performance gap between DMT and no-DMT schools was eliminated when students had teachers with DMT professional development across all three years. 


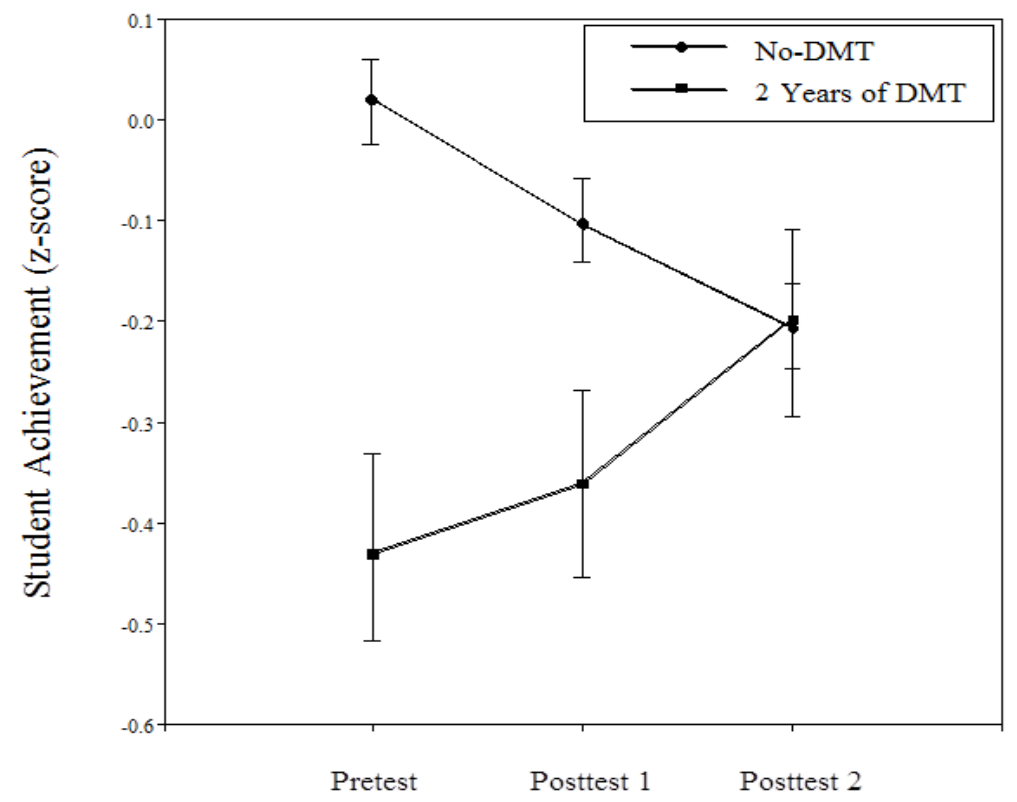

Figure 4. Achievement Data for Students Whose Teachers Participated in the DMT PD for the First Two Years and for Those Whose Teachers Did Not

\section{Discussion}

This study documents the impact of a mathematics professional development program-Developing Mathematical Thinking - on student achievement over time. By focusing on specific elements from the literature on how to effectively build student understanding (Gravemeijer, 1999; Hiebert \& Carpenter, 1992) and by using critical elements to design professional development (Yoon et al., 2007) for working with entire school faculties, we found that we could positively affect student achievement. In particular, this study compared student achievement for teachers who participated in the program, compared to teachers in similar Title 1 schools from the same district, who did not participate in the program.

As noted before, PD has a distal impact upon student achievement, and effect sizes in this study were small. However, results were positive as predicted. Overall, these findings suggest that the DMT professional development had a positive relationship on student achievement. That is, while student achievement in comparison schools was decreasing across time, it was increasing in DMT schools. It is important to note that with the district emphasis on reading over these three years and by placing mathematics instruction in the afternoon and decreasing the time to teach mathematics, one would argue for no change or a decrease in mathematics achievement.

In addition, because the professional development and instructional practices focused on building student understanding and reasoning in mathematics, and the state standardized test focused mostly on rote skills, we were able to demonstrate an increase in this type of knowledge. This provides evidence of the effectiveness of the professional development and leaves open the possibility of showing greater effects with tests that measure more than rote skills. Student achievement in this district was below the mean mathematics achievement for the State. Thus, we do not know how the DMT professional development would work in schools with higher mathematics achievement. That said, DMT did work with students that had lower mathematics achievement.

Research has found that professional development can effect instruction (Desimone et al., 2002) and research has found that quality instruction can affect student achievement (Fennema et al., 1996). Different than many studies, this was not a convenient sample of teachers who volunteered to be part of the study. In contrast, three schools out of six were chosen and $100 \%$ of the teachers were mandated to participate. This alone would decrease any effects in changing teachers' knowledge or practice and in student achievement. As demonstrated in another paper, (Brendefur et al, 2013) by focusing on the five dimensions of DMT - building on students' informal and formal ideas, focusing on conceptual understanding, examining and extending students use of multiple mathematical models, highlighting and discussing mistakes and misconceptions, and staying focused on the structure of mathematics - there is reason to believe these effects on student achievement would translate to all achievement levels. 
The generalizability of the findings from this study is limited by the fact we chose to study elementary schools in one school district. There were many similarities: all six schools were Title I schools and had similar demographics. A side note, however, is that the achievement increases were in spite of much student attrition, which usually has negative effects on reform (Knapp, 1997). And this was accomplished in spite of the district's superintendent and all six principals changing positions over the three years. It may have been our presence that was the catalyst that provided consistency for the schools in which we worked.

In sum, this study demonstrates that quality professional development matters and when implemented well can effect student achievement. Although this study only highlighted the type of instructional practices the professional development promoted, there was an influence which affected student achievement. This professional development had positive effects on the students across all treatment schools.

\section{Conclusions and Implications}

Recent policy documents and increases in accountability around mathematics reform have focused on learning mathematics with understanding (Burkhardt, Schoenfeld, Abedi, Hess, \& Thurlow, 2012; NGA, 2010; NMAP, 2008). The move from teaching traditionally to teaching to build understanding is difficult (Cady, Meier, \& Lubinski, 2006; Kennedy, 2004), but as demonstrated in this study, it can be accomplished in struggling schools. In addition, this type of professional development is timely with the implementation of the CCSS-M's mathematical practices. The DMT principles match many of these practices: (1) make sense of problems and persevere in solving them, (2) reason abstractly and quantitatively, (3) construct viable arguments and critique the reasoning of others, (4) model with mathematics, (5) use appropriate tools strategically, (6) attend to precision, (7) look for and make use of structure, and (8) look for and express regularity in repeated reasoning (NGA, 2010, pp. 6-9) and provide a framework on how to teach mathematics.

This research leads to a number of additional research questions to be pursued within mathematics education. First, future research is needed to evaluate the effectiveness of DMT across a full range of student skill levels, including students who are in special education, gifted or English language development programs. Second, because this PD was whole-school, what are the effects within school? Or in other words, to what degree did each teacher within the program change in regards to beliefs, knowledge and instructional practices and what is the relationship between these factors and achievement. Third, professional development programs similar to this take much time, effort, and resources to implement. We need to understand in greater detail, which aspects of the programs are critical in order to scale up.

\section{References}

Adajian, L. B. (1995). Teachers' professional community and the teaching of mathematics. University of Wisconsin-Madison.

Ball, D. L., Thames, M. T., \& Phelps, G. (2008). Content knowledge for teaching: What makes it so special? Journal of Teacher Education, 59(5), 389-407. https://doi.org/10.1177/0022487108324554

Ball, D., Hill, H., \& Bass, H. (2005). Knowing mathematics for teaching: Who knows mathematics well enough to teach third grade, and how can we decide? . American Educator, 14-46.

Baroody, A. J., Cibulskis, M., Lai, M.-1., \& Li, X. (2004). Comments on the use of learning trajectories in curriculum development and research. Mathematical Thinking and Learning, 6(2), 227-260.

Borko, H., Koellner, K., \& Jacobs, J. (2011). Meeting the challenges of scale: The importance of preparing professional development leaders. Teacher College Record.

Brendefur, J. L., Thiede, K., Strother, S., Bunning, K., \& Peck, D. (2013). Developing mathematical thinking: Changing teachers' knowledge and instruction. Journal of Curriculum and Teaching, 2(2), 62-75. https://doi.org/10.5430/jct.v2n2p62

Brendefur. (2008). Connecting elementary teachers' mathematical knowledge to their instructional practices. The Researcher, 21(2), 1-18.

Bruner, J. S. (1964). The course of cognitive growth. American Psychologist, 19(1), 1-15. https://doi.org/10.1037/h0044160

Burkhardt, H., Schoenfeld, A., Abedi, J., Hess, K., \& Thurlow, M. (2012). Content specifications for the summative assessment of the Common Core State Standards for Mathematics: Smarter Balanced Assessment Consortium. 
Cady, J., Meier, S. L., \& Lubinski, C. A. (2006). The mathematical tale of two teachers: A longitudinal study relating mathematics instructional practices to level of intellectual development. Mathematics Education Research Journal, 18(1), 3-26. https://doi.org/10.1007/BF03217427

Carpenter, T. P., \& Lehrer, R. (1999). Teaching and learning mathematics with understanding. In E. Fennema \& T. Romberg (Eds.), Mathematics Classrooms that Promote Teaching for Understanding (pp. 19 - 32). Mahwah, NJ: Lawerance Erlbaum Associates.

Carpenter, T., Fennema, E., Levi, L., Franke, M. L., \& Empson, S. B. (2000). Children's mathematics: A guide for workshop leaders.

Chernoff, J. J., Flanagan, K. D., McPhee, C., \& Park, J. (2007). Preschool: First findings from the third follow-up of the early childhood longitudinal study, birth cohort (ECLS-B) (NCES 2008-025). In U. S. D. o. Education (Ed.). Washington, DC: National Center for Education Statistics, Institute of Education Sciences.

Clements, \& Sarama, J. (2007). Effects of a preschool mathematics curriculum: Summative research on the Building Blocks project. Journal for Research in Mathematics Education, 38, 136-163.

Clements, D. H., \& Sarama, J. (2004). Learning trajectories in mathematics education. Mathematical thinking and learning, 6(2), 81-89. https://doi.org/10.1207/s15327833mt10602_1

Clements, Xiufeng, L., \& Sarama, J. (2008). Development of a measure of early mathematics achievement using the Rasch model: The Research-Based Early Maths Assessment. Educational Psychology, 28(4), 457-482. https://doi.org/10.1080/01443410701777272

Cobb, P. (2000). Conducting classroom teaching experiments in collaboration with teachers. In A. Kelly \& R. Lesh (Eds.), Handbook of research design in mathematics and science education (pp. 307-334). Mahwah, NJ: Lawrence Erlbaum.

Desimone, L. (2011). A primer on effective professional development. Phi Delta Kappan, 92(6), 68-71. https://doi.org/10.1177/003172171109200616

Desimone, L. M. (2009). Improving impact studies of teachers' professional development: Toward better conceptualizations and measures. Educational Researcher, 38(3), 181-199. https://doi.org/10.3102/0013189X08331140

Desimone, L. M., Porter, A. C., Garet, M. S., Yoon, K. S., \& Birman, B. F. (2002). Effects of professional development on teachers' instruction: Results from a three-year longitudinal study. Educational Evaluation and Policy Analysis, 24(2), 81-112. https://doi.org/10.3102/01623737024002081

Doerr, H. M. (2006). Examining the tasks of teaching when using students' mathematical thinking. Educational Studies in Mathematics, 62(1), 3-24. https://doi.org/10.1007/s10649-006-4437-9

Duncan, G. J., Dowsett, C. J., Claessens, A., Magnuson, K., Huston, A. C., Klebanov, P., \& Brooks-Gunn, J. (2007). School readiness and later achievement. Developmental Psychology, 43, 1428-1446. https://doi.org/10.1037/0012-1649.43.6.1428

Fennema, E., Carpenter, T. P., Franke, M. L., Levi, L., Jacobs, V., \& Emson, S. (1996). A longitudinal study of learning to use children's thinking in mathematics instruction. Journal for Research in Mathematics Education, 27(4), 404-434. https://doi.org/10.2307/749875

Freudenthal, H. (1973). Mathematics as an educational task. Dordrecht, The Netherlands: Reidel.

Freudenthal, H. (1991). Revisiting mathematics education. Dordrecht, The Netherlands: Kluwer.

Garet, M. S., Porter, A. C., Desimone, L., Birman, B. F., \& Yoon, K. S. (2001). What makes professional development effective? Results from a national sample of teachers. American Educational Research Journal, 38(4), 915-945. https://doi.org/10.3102/00028312038004915

Gersten, R., Beckmann, S., Clarke, B., Foegen, A., Marsh, L., Star, J. R., \& Witzel, B. (2009). Assisting students struggling with Mathematics: Response to intervention (RtI) for elementary and middle schools (NCEE 20094060) Washington, DC: Institute of Education Sciences.

Ginsburg, Lee, J. S., \& Boyd, J. S. (2008). Mathematics education for young children: What it is and how to promote it? Social Policy Report, 22(1).

Gravemeijer, K. (1999). How emergent models may foster the constitution of formal mathematics. Mathematical Thinking and Learning, 1(2), 155-177. https://doi.org/10.1207/s15327833mt10102_4 
Gravemeijer, K. (2004). Local instruction theories as means of support for teachers in reform mathematics education. Mathematical Thinking and Learning, 6(2), 105-128. https://doi.org/10.1207/s15327833mt10602_3

Gravemeijer, K. P. E. (1999). How emergent models may foster the constitution of formal mathematics. Mathematical Thinking and Learning, 1, 155-177. https://doi.org/10.1207/s15327833mt10102_4

Gravemeijer, K. P. E., \& van Galen, F. (2003). Facts and algorithms as products of students' own mathematical activity A research companion to principles and standards for school mathematics (pp. 114-122). Reston VA: National Council for Teachers of Mathematics.

Hawley, W. D., \& Valli, L. (2000). Learner-centered professional development. Phi Delta Kappan: Research Bulletin, 27.

Haycock, K. (2001). Closing the achievement gap. Educational Leadership, 58(6), 6-11.

Hiebert, J., \& Carpenter, T. P. (1992). Learning and teaching with understanding. In D. A. Grouws (Ed.), Handbook of Research on Mathematics Teaching and Learning (pp. 65-97). New York: Macmillan.

Hiebert, J., Carpenter, T. P., Fennema, E., Fuson, K. C., Human, P., Murray, H., . . Wearne, D. (1996). Problem solving as a basis for reform in curriculum and instruction: The case of mathematics. Educational Researcher, 25(4), 12-21. https://doi.org/10.3102/0013189X025004012

Hiebert, J., Carpenter, T. P., Fennema, E., Fuson, K. C., Wearne, D., Murray, H., . . Human, P. (1997). Making sense: Teaching and learning mathematics with understanding. Portsmouth, NH: Heinemann.

Jordan, N. C., Kaplan, D., Ramineni, C., \& Locuniak, M. N. (2009). Early math matters: Kindergarten number competence and later mathematics outcomes. Developmental Psychology, 45, 850-867. https://doi.org/10.1037/a0014939

Kennedy, M. M. (1998). Form and substance in in-service teacher education Research Monograph No. 13. Arlington, VA: National Science Foundation.

Kennedy, M. M. (2004). Reform ideals and teachers' practical intentions. Education Policy Analysis Archives, 12(13). https://doi.org/10.14507/epaa.v12n13.2004

Knapp, M. (1995). Teaching for meaning in high-poverty classrooms. New York, NY: Teachers College Press.

Knapp, M. (1997). Between systemic reforms and the mathematics and science classroom: The dynamics of innovation, implementation, and professonal learning. Review of Educational Research, 67(2), 227-266. https://doi.org/10.3102/00346543067002227

Larsen, S., \& Bartlo, J. (2009). The role of tasks in promoting discourse supporting mathematical learning. In L. Knott (Ed.), The role of mathematics discourse in producing leaders of discourse (pp. 77-98). Charlotte, NC: Information Age Publishing.

Lemke, M., Sen, A., Pahike, E., Partelow, L., Miller, D., \& Williams, T. (2004). International outcomes of learning in mathematics literacy and problem solving: Pisa 2003 results from the U.S. perspective. Washington DC: U.S. Department of Education, National Center for Education Statistics.

Linn, G. B., Gill, P., Sherman, R., Vaughn, V., \& Mixon, J. (2010). Evaluating the long-term impact of professional development. Professional Development in Education, 36(4), 679-682.

Ma, L. (1999). Knowing and Teaching Elementary Mathematics. Mahwah, NJ: Lawrence Erlbaum.

Mitchell, J. H., Hawkins, E. F., Stancavage, F. B., \& Dossey, J. A. (2000). Estimation skills, mathematics-in-context, and advanced skills in mathematics Elementary and Secondary Education: National Center for Education Statistics.

Morgan, P., L., Farkas, G., \& Wu, Q. (2009). Five-year growth trajectories of kindergarten children with learning difficulties in mathematics. Journal of Learning Disabilities, 42, 306-321. https://doi.org/10.1177/0022219408331037

Mullis, I. V. S., Martin, M. O., Gonzalez, E. J., \& Chrostowski, S. J. (2004). TIMSS 2003 international mathematics report. Boston, MA: TIMSS \& PIRLS International Study Center, Boston College.

Newmann, F. M., \& Associates. (1996). Authentic achievement: Restructuring schools for intellectual quality. San Francisco, CA: Jossey Bass.

NGA. (2010). Common core state standards for mathematics. Washington DC: National Governors Association and 
the Council of Chief State School Officers.

NMAP. (2008). Foundations for success: The final report of the National Mathematics Advisory Panel. Washington D.C.: U.S. Department of Education, Office of Planning, Evaluation and Policy Development.

NRC. (2001). Adding it up: Helping children learn mathematics. Washington DC: National Academy Press.

NRC. (2009). Mathematics learning in early childhood: Paths toward excel $\neg$ lence and equity. Washington, DC: The National Academies Press.

Reese, C. M., Miller, K. E., Mazzeo, J., \& Dossey, J. A. (1997). NAEP 1996 Mathematics Report Card for the Nation and the States. Washington, DC: National Center for Education Statistics.

Schifter, D. (1996). What's happening in math class? (Vol. 1: Envisioning new practices through teacher narratives). New York: Teachers College Press.

Simon, M. (2006). Key developmental understandings in mathematics: A direction for investigating and establishing learning goals. Mathematical Thinking and Learning, 8(4), 359-371. https://doi.org/10.1207/s15327833mt10804_1

Simon, M. A. (1995). Reconstructing mathematics pedagogy from a constructivist perspective. Journal for Research in Mathematics Education, 26, 114-145. https://doi.org/10.2307/749205

Simon, M., \& Tzur, R. (2004). Explicating the role of mathematical tasks in conceptual learning: An elaboration of the hypothetical learning trajectory. Mathematical thinking and learning, 6(2), 91-104. https://doi.org/10.1207/s15327833mt10602_2

Sztajn, P. (2011). Standards for reporting mathematics professional development in research studies. Journal for Research in Mathematics Education, 42(3), 220-236.

Treffers, A. (1987). Three dimensions: A model of goal and theory description in mathematics instruction - The Wiskobas Project. Dordrecht, The Netherlands: Reidel. https://doi.org/10.1007/978-94-009-3707-9

Webb, N. (2007). Issues related to judging the alignment of curriculum standards and assessments. Applied Measurement in Education, 20(1), 7-25. https://doi.org/10.1080/08957340709336728

Yoon, K. S., Duncan, T., Wen-Yu Lee, S., Scarloss, B., \& Shapley, K. (2007). Reviewing the evidence on how teacher professional development affects student achievement. Washington, DC: National Center for Educational Evaluation and Regional Assistance, Institute of Education Sciences, U.S. Dept. of Education. 